\title{
Structural and Optical Properties of Thermally Oxidized Zirconium Dioxide Films
}

\author{
Venkataiah Sunke and Uthanna Suda \\ Department of Physics, Sri Venkateswara University, Tirupati - 517 502, India \\ Email address: uthanna@rediffmail.com, svt487@gmail.com
}

Keywords: $\mathrm{ZrO}_{2}$ thin films; Magnetron sputtering; Thermal oxidation; Structure, Optical properties.

\begin{abstract}
Zirconium oxide $\left(\mathrm{ZrO}_{2}\right)$ thin films were grown by thermal oxidation of metallic zirconium films deposited by sputtering of zirconium target by DC magnetron sputtering technique. The zirconium films were thermally oxidized in oxygen atmosphere at temperatures in the range $300-500^{\circ} \mathrm{C}$. The as-deposited and oxidized films were characterized for chemical composition by energy dispersive X-ray analysis, structure by X-ray diffraction, chemical binding configuration with Fourier transform infrared spectroscopy and optical absorption using UV-Vis NIR spectrophotometer. Metallic zirconium film was polycrystalline in nature with hexagonal structured $\mathrm{Zr}$. The films oxidized at $300^{\circ} \mathrm{C}$ were of mixed phase of $\mathrm{Zr}$ and $\mathrm{ZrO} 2$. The zirconium films were transformed into monoclinic structured $\mathrm{ZrO}_{2}$ with polycrystalline in nature at oxidation temperature of $400^{\circ} \mathrm{C}$. Crystallite size of the $\mathrm{ZrO}_{2}$ films increased from $19 \mathrm{~nm}$ to $27 \mathrm{~nm}$ with increase of oxidation temperature form $400^{\circ} \mathrm{C}$ to $500^{\circ} \mathrm{C}$. The optical band gap increased from $5.42 \mathrm{eV}$ to $5.46 \mathrm{eV}$ and refractive index decreased from 2.05 to 2.02 with increase of oxidation temperature from $400^{\circ} \mathrm{C}$ to $500^{\circ} \mathrm{C}$.
\end{abstract}

\section{Introduction}

The combination of electrical, mechanical and optical properties of zirconium dioxide $\left(\mathrm{ZrO}_{2}\right)$ find useful in wide range of applications. It is thermally and chemically stable compound which is potential for protective coating for application in corrosive, high temperature and harsh environments [1]. It has high dielectric constant (25) and thermodynamically stable with silicon, hence a promising substitute for silicon dioxide in gate dielectrics (transistor) with low leakage current densities [2, 3]. It is widely used catalyst in artificial photosynthesis and photocatalytic decomposition of water and carbon dioxide [4]. Nonstoichiometric zirconium dioxide exhibit switching behavior with good retention characteristics in high and low resistance states [5]. Because of its high refractive index, high transparency, wide band gap and low optical losses in the visible and infrared ranges find applications as high reflectivity mirrors and active optoelectronic devices [6], high power lasers [7] and light emitting diodes [8]. It is also used as buffer layer in superconducting coatings [9] and sensing of oxygen gas [10]. These wide range of applications mainly based on its property of polymorphism. It exists in three different crystalline phases namely monoclinic, tetragonal and cubic structured zirconium dioxide in thin films form based on the process temperature [11,12]. These different phases can be tailored made in thin films achieve required hardness, refractive index and optical band gap. Various physical deposition techniques such as thermal oxidation of zirconium films [12,13], electron beam evaporation [14-17], pulsed laser deposition [18,19], vacuum arc deposition [20,21], DC magnetron sputtering [22-25], RF magnetron sputtering [26-30], molecular beam epitaxy [31], and chemical deposition methods namely, chemical bath deposition [32], spray pyrolysis [33], sol-gel process [34-36] and atomic layer deposition [37,38] were employed for the growth of zirconium dioxide thin films. Among these techniques, magnetron sputtering has the advantage in the growth of films on large area substrates and at low substrate temperatures. There are various sputter parameters such as substrate temperature, substrate bias, sputter pressure and sputter power mainly control the physical properties of the deposited films. Thermal oxidation of metallic films leads to the growth metal oxide films. Bae at al. [12] prepared $\mathrm{ZrO}_{2}$ thin films by two step process by deposition of metallic 
zirconium films with and without substrate bias voltage followed by thermal oxidation. The films formed with substrate bias leads to high dielectric constant and low leakage currents. Larijani et al. [13] reported that the optical band gap of $\mathrm{ZrO}_{2}$ thin films formed by thermal oxidation of sputter deposited zirconium films increased from $3.85 \mathrm{eV}$ to $3.96 \mathrm{eV}$ and the refractive index decreased from 2.8 to 2.2 with increase of oxidation temperature from $400^{\circ} \mathrm{C}$ to $550^{\circ} \mathrm{C}$ respectively. High refractive index and large band gap of zirconium dioxide thin films find application in broad band filters and active optoelectronic devices. Hence in this investigation, an attempt is made on the growth of zirconium dioxide thin films by thermal oxidation of zirconium films prepared by DC magnetron sputtering of metallic zirconium target. The influence of oxidation temperature on the structural and surface morphology, chemical binding configuration and optical properties of the zirconium dioxide films were systematically studies.

\section{Experimental Details}

Metallic thin films of zirconium were deposited onto quartz, aluminium and n- silicon (100) substrates by sputtering of zirconium target $(50 \mathrm{~mm}$ diameter) using DC magnetron sputter deposition method. The sputter up configuration was used for growth of the films. Schematic diagram of the sputter system employed deposition of zirconium films is shown in Fig. 1. The sputter chamber was evacuated with diffusion pump and rotary pump combination. Pinning and Pirani gauges were used for measurement of pressure in the sputter chamber. Quartz and aluminium substrates were cleaned with degreasing solution followed by washing in deionized water. Later, the substrates were ultrasonically cleaned in distilled water for 15 minutes and dried with nitrogen gas before transfer in to the sputter chamber. Silicon substrates were cleaned with standard RCA (Radio Corporation of America) procedure. The silicon substrates were immersed in a mixture of ammonia, hydrogen peroxide and water with ratio of $1: 1: 5$ for 10 minutes at temperature of $75^{\circ} \mathrm{C}$ to remove the organic contaminants. In order to remove the metallic contaminants, the substrates were dipped in the solution contained hydrochloric acid, hydrogen peroxide and water with ratio of 1:1:6 for 10 minutes at $75^{\circ} \mathrm{C}$. Finally, the silicon substrates were immersed in the solution with mixture of hydrofluoric acid and water with ratio of 1:50 for 20 seconds followed by rinsing in distilled water and blown with nitrogen gas in order to remove the native oxide before loaded into the sputter chamber for deposition of the films. The target to substrate distance maintained was $70 \mathrm{~mm}$. After achieving the base pressure of $5 \times 10^{-6}$ Torr, pure argon gas was admitted in to the sputter chamber through fine controlled needle valves to achieve the sputter pressure of $6 \times 10^{-3}$ Torr. The films were deposited on the unheated substrates and DC power fed to the sputter target was $60 \mathrm{~W}$. The deposition conditions fixed for the growth of zirconium films are given in Table 1.

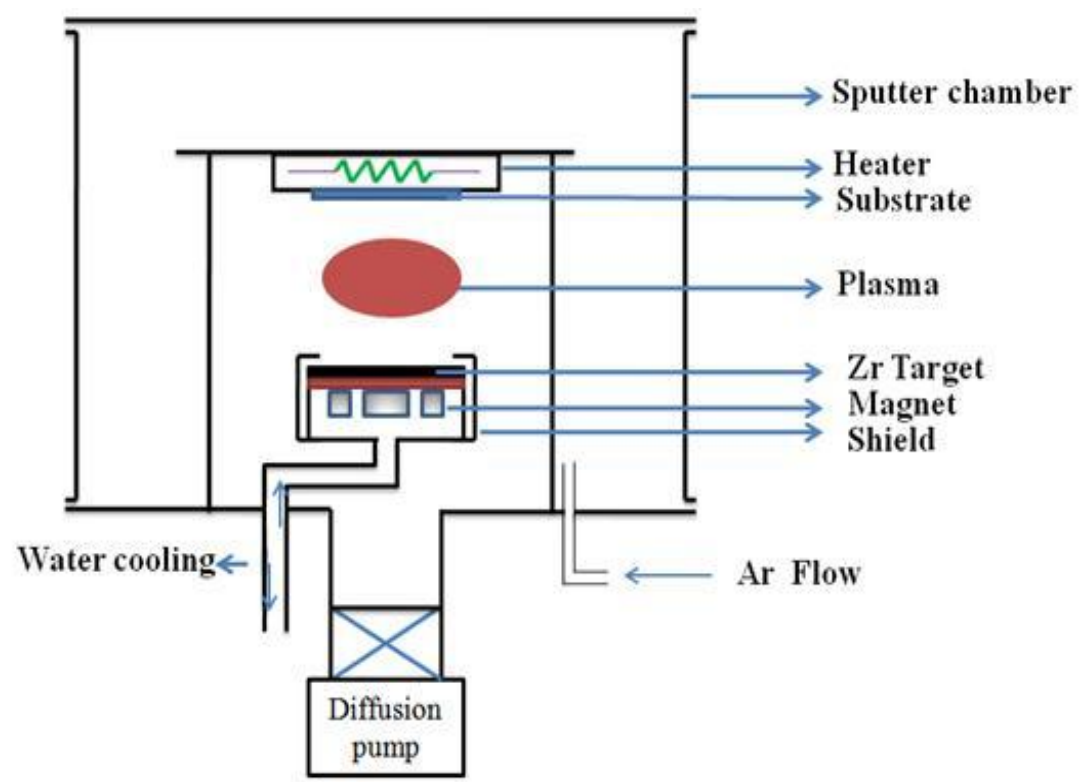

Figure 1. Schematic diagram of magnetron sputter system for deposition of zirconium thin films. 
The As-deposited metallic zirconium films were thermally oxidized in oxygen atmosphere for two hours at different temperatures in the range $300-500^{\circ} \mathrm{C}$ in order to transform zirconium into $\mathrm{ZrO}_{2}$ films. As-deposited $\mathrm{Zr}$ films and thermally oxidized $\mathrm{ZrO}_{2}$ films were characterized for chemical composition by energy dispersive X-ray analysis using Oxford Instruments Inca Penta FETX3.

Table 1. Deposition conditioned for the growth of zirconium thin film.

$\begin{array}{ll}\text { Deposition method } & : \text { DC magnetron sputtering } \\ \text { Sputter target } & : \text { Zirconium }(50 \mathrm{~mm} \text { dia. }) \\ \text { Target to substrate distance } & : 70 \mathrm{~mm} \\ \text { Base pressure } & : 5 \times 10^{-6} \mathrm{Torr} \\ \text { Sputter pressure } & : 6010^{-3} \mathrm{Torr} \\ \text { Sputter power } & : 120 \mathrm{Wec}\end{array}$

Crystallographic structure and crystallite size of the films were determined with X-ray diffraction (XRD) using copper K $\alpha$ radiation with wavelength of $0.15406 \mathrm{~nm}$. Chemical binding configuration of the films was analyzed with Fourier Transform Infrared spectroscope (FTIR) (Thermo-Nicolet 6700 ) in the wavenumber range $400-2000 \mathrm{~cm}^{-1}$. Surface morphology of the films was examined with scanning electron microscope. Optical absorption in the films was recorded using UV-Vis-NIR double beam spectrophotometer (JASCO V-570) in the wavelength range $185-900 \mathrm{~nm}$ in order to determine the optical band gap and refractive index.

\section{Results and Discussion}

Thickness of the zirconium film determined with Veeco Dektak depth profilometer was $240 \mathrm{~nm}$. Chemical composition of zirconium films and the films oxidized at different temperatures were determined with energy dispersive X-ray analysis (EDAX). Fig. 2 shows the EDAX of zirconium and zirconium dioxide films. The EDAX spectrum of $\mathrm{Zr}$ film contains the peak of zirconium without any other elements which indicated the growth of metallic zirconium as shown in Fig. 2a. The film oxidized at $300^{\circ} \mathrm{C}$ contains the peaks of oxygen along with zirconium (Fig. 2b). As the oxidation temperature increased to $400^{\circ} \mathrm{C}$ and $500^{\circ} \mathrm{C}$ the content of oxygen increased the content of zirconium decreased as shown in Figs. $2 \mathrm{c}$ and $2 \mathrm{~d}$. Chemical composition of the films was calculated from the intensity of the elemental peaks and their respective sensitivity factors. Chemical composition of as-deposited and oxidized films are given in the Table 2. The as-deposited films were zirconium. The film oxidized at $300^{\circ} \mathrm{C}$ contain the chemical composition of $\mathrm{Zr}=60.5$ at. $\%$ and $\mathrm{O}=39.5$ at.\%. At the oxidation temperature of $400^{\circ} \mathrm{C}$ the content of oxygen in the films increased to 64.8 at.\% and zirconium decreased to 35.2 at.\%. Further increase of oxidation temperature to $500^{\circ} \mathrm{C}$ the films contained the $\mathrm{Zr}=34.3$ at. $\%$ and $\mathrm{O}=65.7$ at. $\%$. 

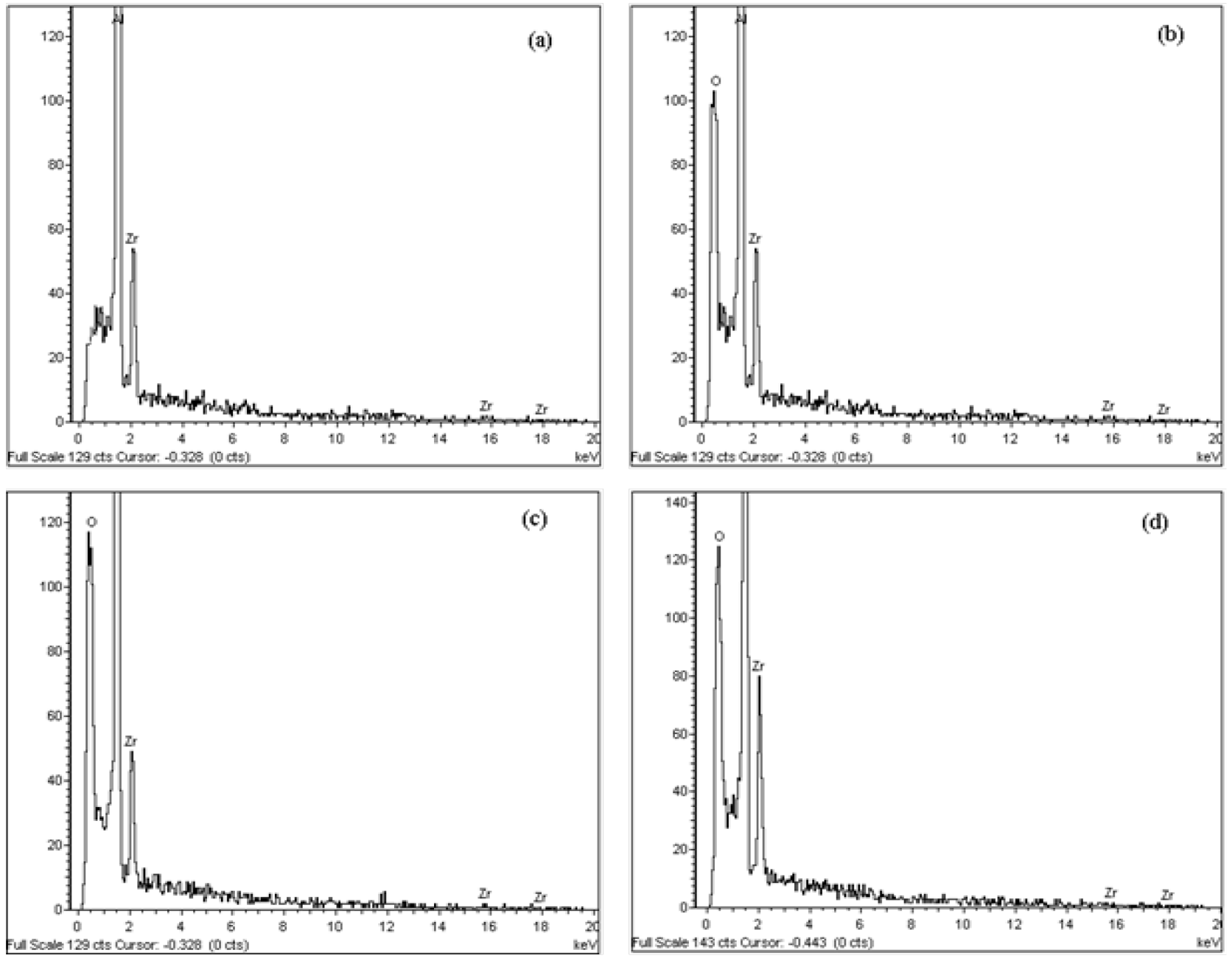

Figure 2. EDAX spectra of thermally oxidized $\mathrm{ZrO}_{2}$ films: (a) as-deposited $\mathrm{Zr}$ film and thermally oxidized at temperatures of (b) $300^{\circ} \mathrm{C}$, (b) $400^{\circ} \mathrm{C}$ and (b) $500^{\circ} \mathrm{C}$.

Table 2. Chemical composition of thermally oxidized $\mathrm{ZrO}_{2}$ films.

\begin{tabular}{|c|c|c|}
\hline Sample & Zirconium (at.\%) & Oxygen (at.\%) \\
\hline Zr film & 100.0 & --- \\
\hline Oxidized at $300^{\circ} \mathrm{C}$ & 60.5 & 39.5 \\
\hline Oxidized at $400^{\circ} \mathrm{C}$ & 35.2 & 64.8 \\
\hline Oxidized at $500^{\circ} \mathrm{C}$ & 34.3 & 65.7 \\
\hline
\end{tabular}

It clearly indicated that the films oxidized at $300^{\circ} \mathrm{C}$ were of mixed phase of $\mathrm{Zr}$ and $\mathrm{ZrO}_{2}$. The films annealed at $400^{\circ} \mathrm{C}$ and above were of nearly stoichiometric $\mathrm{ZrO}_{2}$. It is also confirmed in the $\mathrm{X}$-ray diffraction studies as discussed in the next section.

\subsection{Structural properties}

Crystallographic structure of the films was determined from the X-ray diffraction. Fig.3 shows the X-ray diffraction profiles of as-deposited $\mathrm{Zr}$ and thermally oxidized $\mathrm{ZrO}_{2}$ films. As-deposited films contain the diffraction peak at $29.2^{\circ}$ indicated (001) reflection of hexagonal structured zirconium (JCPDS card No. 26-1399). It revealed the as-grown zirconium films were of polycrystalline in nature. The films oxidized at temperature of $300^{\circ} \mathrm{C}$ contained $\mathrm{X}$-ray diffraction peak (111) related to $\mathrm{ZrO}_{2}$ and (201) correspond to $\mathrm{Zr}$. It clearly indicated that the films oxidized at $300^{\circ} \mathrm{C}$ were of mixed phase of $\mathrm{Zr}$ and $\mathrm{ZrO}_{2}$. The films oxidized at temperature of $400^{\circ} \mathrm{C}$ exhibited four diffraction peaks at $26.7^{\circ}, 46.9^{\circ}$ and $56.9^{\circ}$ and $60.1^{\circ}$ related to the $(\overline{1} 11),(211),(310)$ and (302)reflections of monoclinic phase of $\mathrm{ZrO}_{2}$. It is in good agreement with the standard X-ray 
diffraction data of JCPDS card NO. 78-1807. It confirmed that the $\mathrm{Zr}$ films were transformed in to $\mathrm{ZrO}_{2}$ films at the oxidation temperature of $400^{\circ} \mathrm{C}$. Further increase of oxidation temperature to $500^{\circ} \mathrm{C}$ intensity of the diffraction peaks enhanced with the presence of additional reflections of (111) and (132) of $\mathrm{ZrO}_{2}$. Lajirani et al. [13] noticed that the sputter deposited $\mathrm{Zr}$ films were transformed in to $\mathrm{ZrO}_{2}$ films at the oxidation temperature of $500^{\circ} \mathrm{C}$ with presence of mixed monoclinic and tetragonal phases. Hembram et al. [22] achieved single phase zirconium dioxide thin films at oxidation temperature of $600^{\circ} \mathrm{C}$ in magnetron sputtered films. In the present investigation, magnetron sputtered zirconium thin films were transformed in to single phase monoclinic $\mathrm{ZrO}_{2}$ at low oxidation temperature of $400^{\circ} \mathrm{C}$. At higher temperature of $500^{\circ} \mathrm{C}$ the grown crystallites were of larger in size. The thickness of the $\mathrm{ZrO}_{2}$ films was higher when compared with the zirconium films. The thickness of the films oxidized at $400^{\circ} \mathrm{C}$ was $255 \mathrm{~nm}$, further increased to $280 \mathrm{~nm}$ at higher temperature of $500^{\circ} \mathrm{C}$. Increase of film thickness with oxidation temperature was due to the large unit cell volume of $\mathrm{ZrO}_{2}$ than zirconium. As the oxidation temperature increased the diffusion of oxygen into the $\mathrm{Zr}$ films takes place and transformed in $\mathrm{toZrO}_{2}$. The crystallite size (D) of the as-deposited $\mathrm{Zr}$ and thermally oxidized $\mathrm{ZrO}_{2}$ films was calculated from the full width at half maximum intensity $(\beta)$ of the X-ray diffraction angle $(\theta)$ of thepeak and the wavelength $(\lambda)$ of copper X-ray radiation employing Debye-Scherrer's relation [39] assuming that no strains were developed in the films,

$$
D=K \lambda / \beta \cos \theta,
$$

where $\mathrm{K}$ is a constant with the value of 0.89 for copper $\mathrm{X}$-ray radiation and $\theta$ the diffraction angle. The full width at half maximum intensity of the films decreased with increase of oxidation temperature. Crystallite size of the zirconium film was $15 \mathrm{~nm}$. As the oxidation temperature increased from $400^{\circ} \mathrm{C}$ to $500^{\circ} \mathrm{C}$ the crystallite size increased from $19 \mathrm{~nm}$ to $27 \mathrm{~nm}$. It revealed that the crystallinity of the $\mathrm{ZrO}_{2}$ films was accelerated by the temperature.

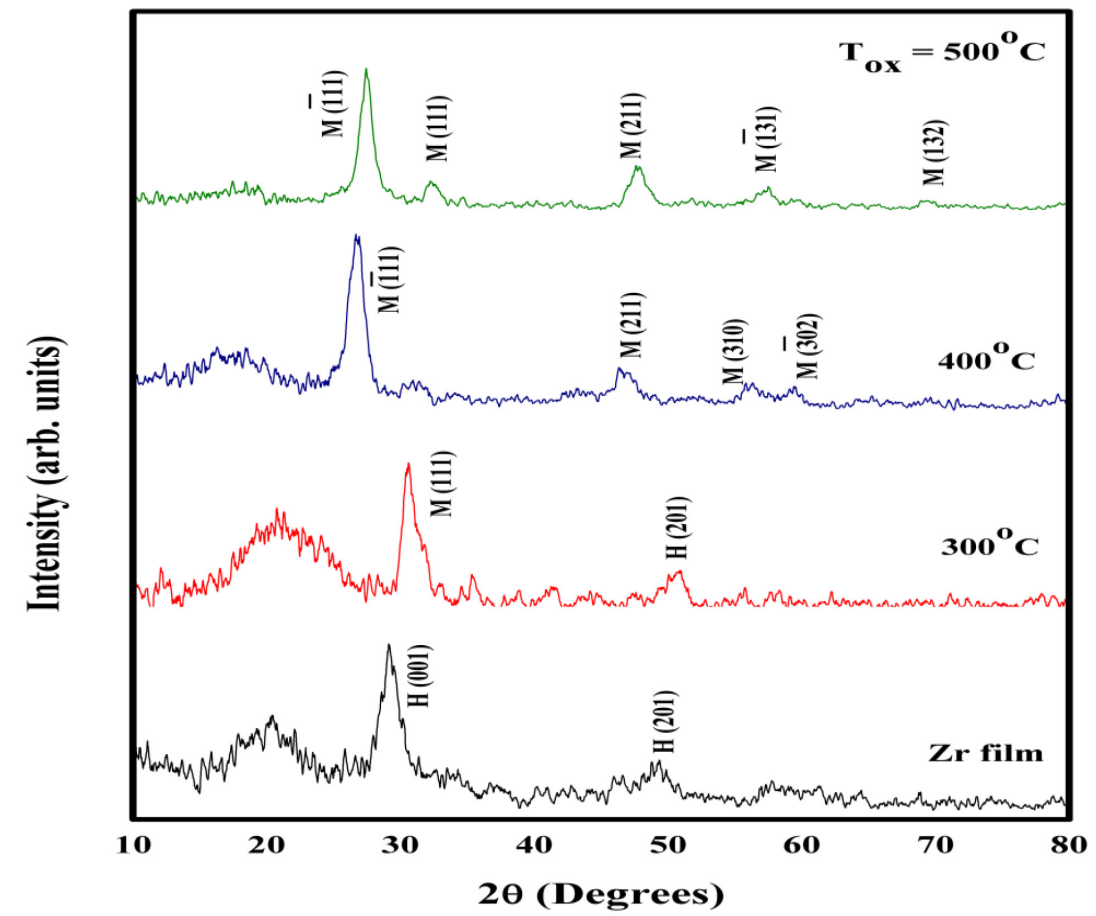

Figure 3. X-ray diffraction profiles of $\mathrm{Zr}$ and thermally oxidized $\mathrm{ZrO}_{2}$ films.

Surface morphology of the films was analyzed with scanning electron microscope. Fig. 4 shows the scanning electron micrographs of $\mathrm{Zr}$ and the $\mathrm{ZrO}_{2}$ films oxidized at different temperatures. The micrographs of the films showed the smooth surface. When the oxidation temperature increased there was an increase in the size of spherical shaped grains. These grains were uniformly distributed over the surface of the films. Fourier transform infrared transmittance spectra was recorded on the films formed on silicon substrates. Fig. 5 shows Fourier transform 
infrared transmittance spectra of zirconium films oxidized at temperatures of $400^{\circ} \mathrm{C}$ and $500^{\circ} \mathrm{C}$. The spectra showed the broad band between $400 \mathrm{~cm}^{-1}$ and $500 \mathrm{~cm}^{-1}$. The films oxidized at $400^{\circ} \mathrm{C}$ showed the absorption bands at $420 \mathrm{~cm}^{-1}, 505 \mathrm{~cm}^{-1}, 605 \mathrm{~cm}^{-1}$ and $739 \mathrm{~cm}^{-1}$ which were related to the vibration modes of monoclinic $\mathrm{ZrO}_{2}$. The films oxidized at higher temperature of $500^{\circ} \mathrm{C}$ exhibited decrease in the intensity of $505 \mathrm{~cm}^{-1}$ absorption band and absence of $739 \mathrm{~cm}^{-1}$ band.
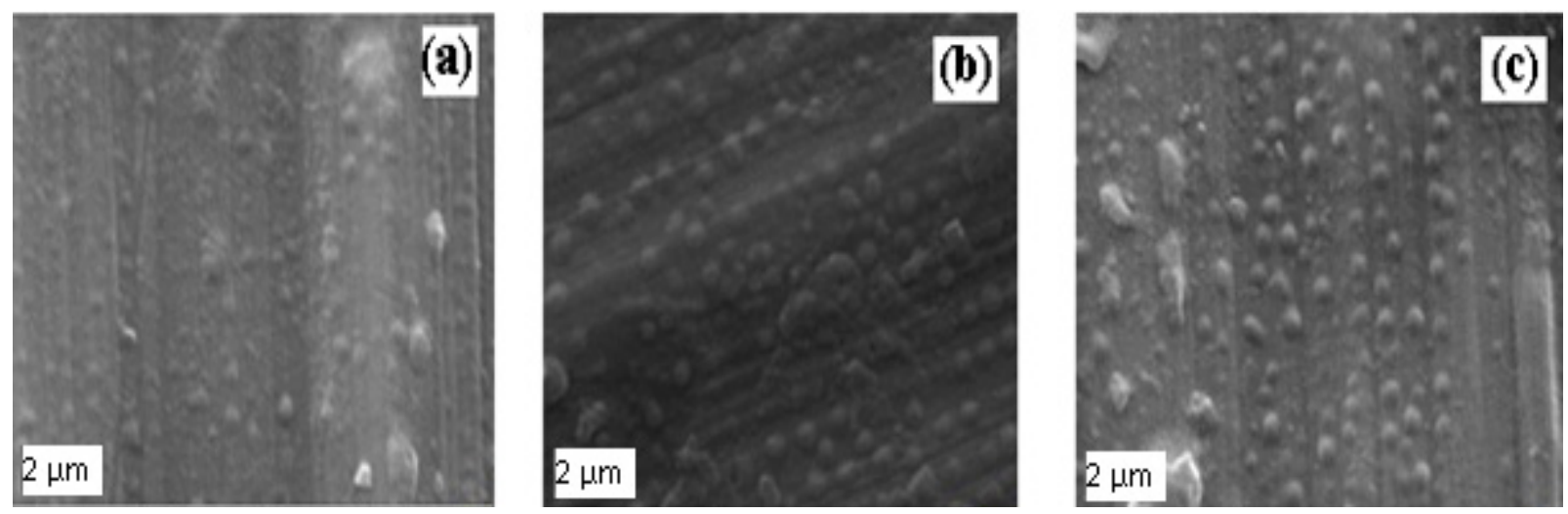

Figure 4. Scanning electron micrographs of $\mathrm{ZrO}_{2}$ films oxidized at (a) $300^{\circ} \mathrm{C}$, (b) $400^{\circ} \mathrm{C}$ and (c) $500^{\circ} \mathrm{C}$.

In the literature, it was reported that the absorption bands at $410 \mathrm{~cm}^{-1}, 520 \mathrm{~cm}^{-1}, 610 \mathrm{~cm}^{-1}$ and $720 \mathrm{~cm}^{-1}$ were the characteristic vibration modes of themonoclinic phase of $\mathrm{ZrO}_{2}[19,40]$. FTIR studies also confirmed that the films oxidized at temperature of $400^{\circ} \mathrm{C}$ and above were of $\mathrm{ZrO}_{2}$.

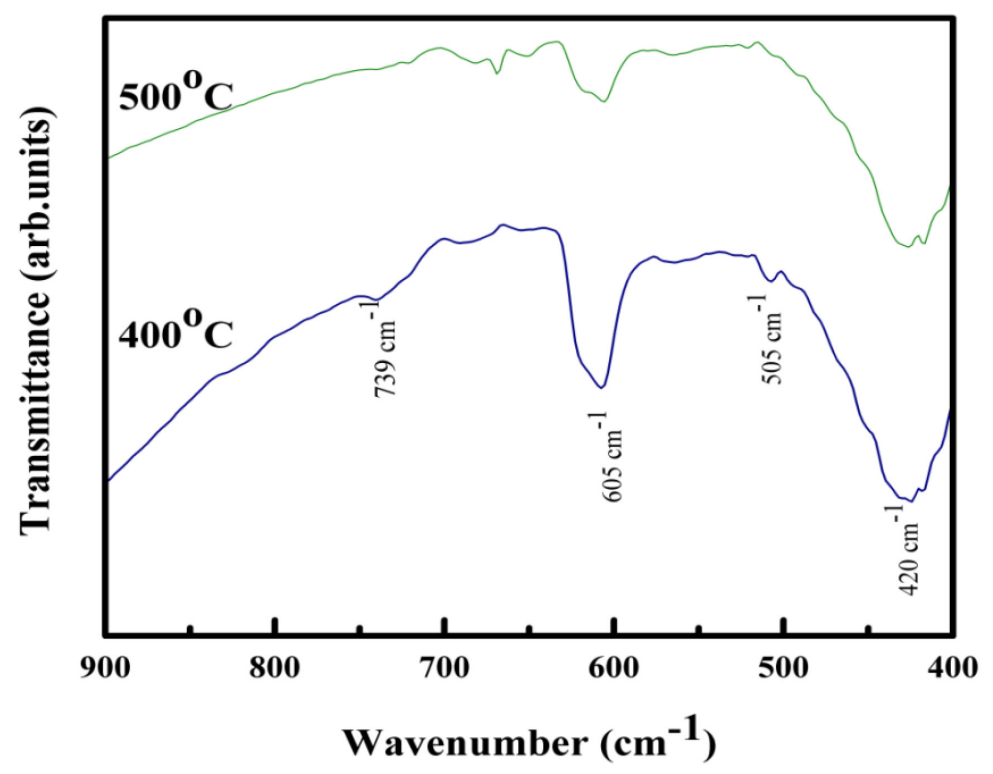

Figure 5. Fourier transform infrared transmittance spectra of $\mathrm{ZrO}_{2}$ films oxidized at $400^{\circ} \mathrm{C}$ and $500^{\circ} \mathrm{C}$.

\subsection{Optical properties}

Optical transmittance of metallic zirconium films formed on quartz substrate and thermally oxidized zirconium dioxide films were recorded in the wavelength range $185-900 \mathrm{~nm}$ in order to determine the optical absorption and optical band gap. Fig. 6 shows the optical transmittance spectra of $\mathrm{Zr}$ and $\mathrm{ZrO}_{2}$ thin films. $\mathrm{Zr}$ films showed the optical transmittance of about 3\% due to the reflective nature of the metallic films. The films oxidized at $300^{\circ} \mathrm{C}$ exhibited the transmittance of about $50 \%$ at (wavelength of $550 \mathrm{~nm}$ ). As the oxidation temperature increased to $400^{\circ} \mathrm{C}$ the transmittance enhanced to $80 \%$ and at higher temperature of $500^{\circ} \mathrm{C}$ it further increased to $85 \%$ due to the oxide nature of the films. Low transmittance in the films oxidized at $300^{\circ} \mathrm{C}$ was mainly due 
the mixed phase of $\mathrm{Zr}$ and $\mathrm{ZrO}_{2}$ as noted in X-ray diffraction. The films oxidized at $400^{\circ} \mathrm{C}$ and above were of fully transformed in to $\mathrm{ZrO}_{2}$. The fundamental optical absorption edge of the films shifted towards lower wavelength side with increase of oxidation temperature. The absorption coefficient $(\alpha)$ of the films was calculated from the optical transmittance (T) and the thickness (t)using the relation

$$
\alpha=(1 / t) \ln T .
$$

By assuming the direct transitions transition takes place in the films that is the transition of electrons from the top of the valance band to the bottom of the conduction band due to the absorption of photon, the optical band gap $\left(E_{g}\right)$ of the films was determined from the optical absorption coefficient and photon energy ( $\mathrm{h} v)$ using the Tauc's relation [41]

$$
(\alpha h v)^{2}=A\left(h v-E_{g}\right),
$$

where $\mathrm{A}$ is the edge width parameter. From the plots of $(\alpha h v)^{2}$ versus photon energy the optical band gap of zirconium dioxide films was evaluated by extrapolating the linear portion of the plots to $\alpha=0$. Fig. 7 shows the plots of $(\alpha h v)^{2}$ versus photon energy of $\mathrm{Zr}$ and thermally zirconium dioxide films. The optical band of the films oxidized at $300^{\circ} \mathrm{C}$ was $3.49 \mathrm{eV}$. As the oxidation temperature from $400^{\circ} \mathrm{C}$ to $500^{\circ} \mathrm{C}$ the optical band gap of the films increased from $5.42 \mathrm{eV}$ to $5.48 \mathrm{eV}$ respectively. The low optical band gap in the films oxidized at $300^{\circ} \mathrm{C}$ was due to the mixed phase of $\mathrm{Zr}$ and $\mathrm{ZrO}_{2}$ films. These results clearly indicated that the films oxidized at $400^{\circ} \mathrm{C}$ and above were transformed in to $\mathrm{ZrO}_{2}$. In the literature, Lirijani et. al. [13] was reported that the optical band gap increased from $3.85 \mathrm{eV}$ to $3.96 \mathrm{eV}$ with increase of oxidation temperature in the magnetron sputtered films. Pakma et al. [32] noticed the optical band gap was in the range 2.40 $3.96 \mathrm{eV}$ depending on the constituents in the chemical bath and the process temperature of the films formed by chemical bath deposition. Korkmaz et al. [20] reported that the band gap increased from $3.85 \mathrm{eV}$ to $3.96 \mathrm{eV}$ with increase of annealing temperature from $350^{\circ} \mathrm{C}$ to $550^{\circ} \mathrm{Crespectively} \mathrm{in} \mathrm{the}$ films formed by thermionic vacuum arc method. Hembram et al. [22] noticed that the optical band gap of as-deposited $\mathrm{ZrO}_{2}$ films was $4.37 \mathrm{eV}$ and it increased to $4.83 \mathrm{eV}$ when annealed at $600^{\circ} \mathrm{C}$ in magnetron sputtered films. Zhao et al. [26] reported the optical band gap of $5.74 \mathrm{eV}$ in $\mathrm{RF}$ magnetron sputtered films at substrate bias voltage of $-110 \mathrm{~V}$. It clearly indicated that the optical band gap increased with the annealing, oxidation temperature or substrate bias voltage due to filling up of oxygen ion vacancies and produced $\mathrm{ZrO}_{2}$ films. Refractive index of the films determined with ellipsometry at wavelength $550 \mathrm{~nm}$. The refractive index of the films decreased from 2.05 to 2.02 increase of oxidation temperature from $400^{\circ} \mathrm{C}$ to $500^{\circ} \mathrm{C}$ respectively. Larijani et al. [13] noticed high refractive index of 2.8 in the films oxidized at $400^{\circ} \mathrm{C}$ and it decreased to 2.2 in at temperature of $550^{\circ} \mathrm{C}$. 


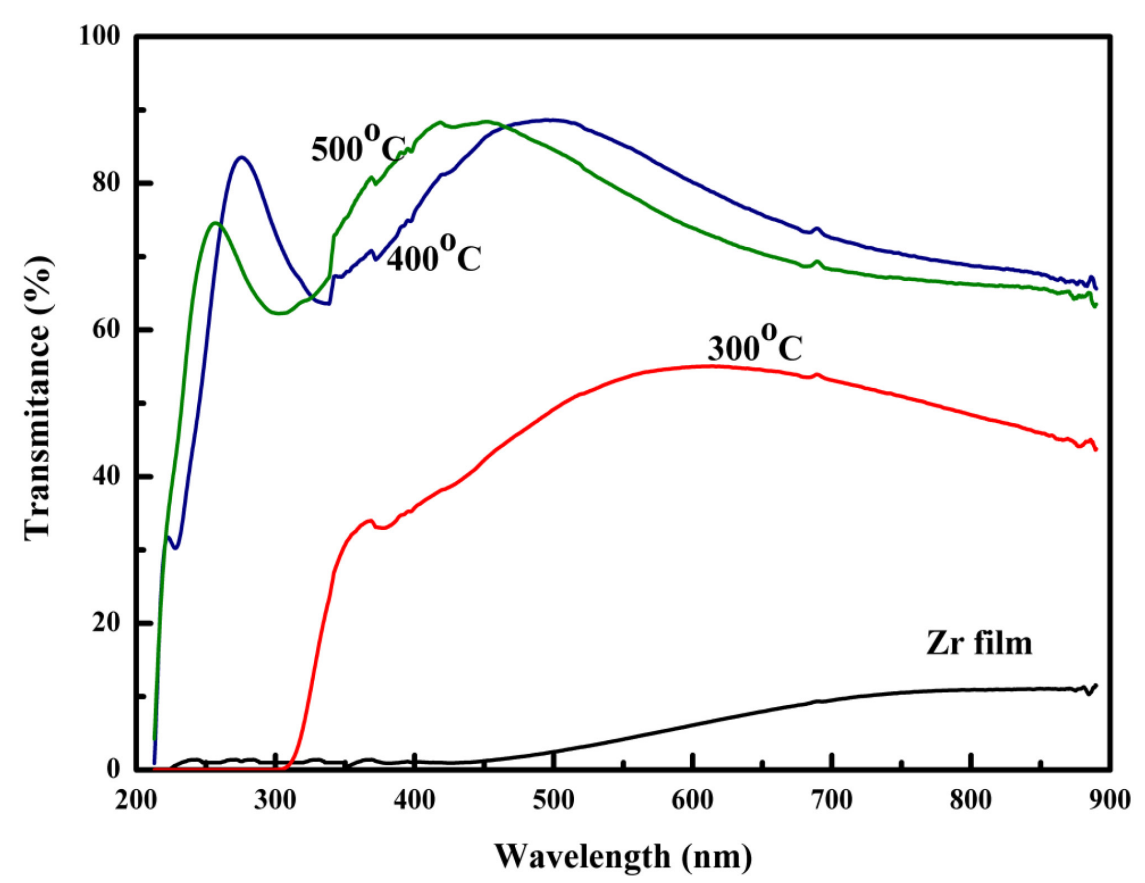

Figure 6. Optical transmittance spectra of $\mathrm{Zr}$ and $\mathrm{ZrO}_{2}$ films.

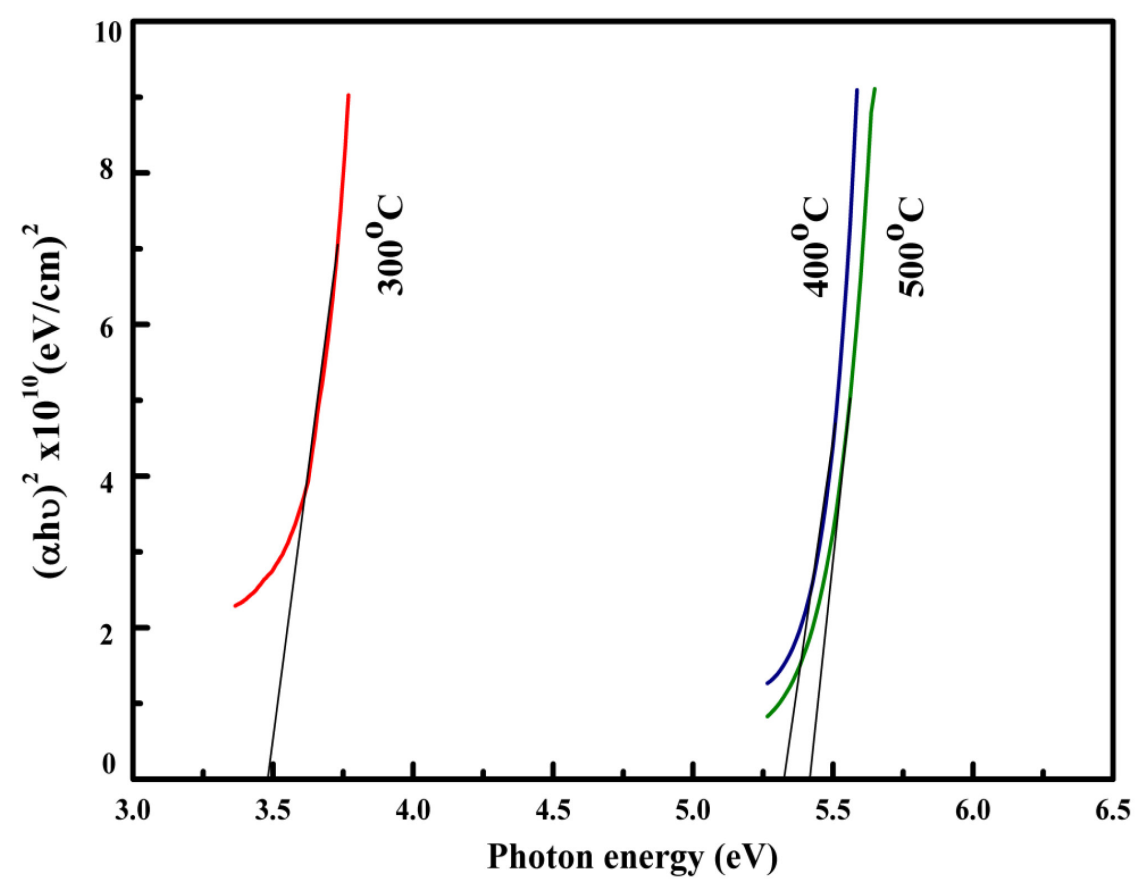

Figure 7. Plots of $(\alpha h v)^{2}$ versus photon energy of thermally oxidized $\mathrm{ZrO}_{2}$ films.

\section{Conclusions}

Thin films of zirconium $(\mathrm{Zr})$ were formed by DC magnetron sputtering method followed by thermal oxidation to transform into zirconium dioxide $\left(\mathrm{ZrO}_{2}\right)$. As-deposited $\mathrm{Zr}$ and thermally oxidized $\mathrm{ZrO}_{2}$ films were physically characterized for their chemical composition, structure and optical properties. The effect of oxidation temperature on the physical properties was systematically investigated. The as-deposited $\mathrm{Zr}$ films were polycrystalline in nature with hexagonal structure with crystallite size of $12 \mathrm{~nm}$. The films oxidized at $300^{\circ} \mathrm{C}$ were mixed phase of zirconium and zirconium dioxide. While those oxidized at temperature of $400^{\circ} \mathrm{C}$ and above were of $\mathrm{ZrO}_{2}$. The crystallite size of the zirconium dioxide films increased from $19 \mathrm{~nm}$ to $27 \mathrm{~nm}$ with increase of oxidation temperature. Scanning electron micrographs of zirconium dioxide films exhibited the 
growth of spherical shaped grains. Infrared spectroscopic studies showed the characteristic vibrational modes of $\mathrm{ZrO}_{2}$ in the films oxidized at temperatures $\geq 400^{\circ} \mathrm{C}$. The optical transmittance of the films increased with increase of oxidation temperature and the fundamental optical absorption edge shifted towards lower wavelength side. The optical band gap of zirconium dioxide films evaluated from the Tauc's plots increased from $5.42 \mathrm{eV}$ to $5.46 \mathrm{eV}$ with increase of oxidation temperature from $400^{\circ} \mathrm{C}$ to $500^{\circ} \mathrm{C}$ respectively. The refractive index of zirconium dioxide films determined from ellipsometry decreased from 2.05 to 2.02 with increase of oxidation temperature from $400^{\circ} \mathrm{C}$ to $500^{\circ} \mathrm{C}$. In conclusion, zirconium dioxide films grown by thermal oxidation at temperatures $\geq 400^{\circ} \mathrm{C}$ will be quite useful for application in the broad band filters for active optoelectronic devices.

\section{Acknowledgements}

One of the authors, S. Venkataiah is thankful to the University Grants Commission, India for the award of UGC-BSR-RFSMS Junior Research Fellowship. Dr. S. Uthanna is thankful to the University Grants Commission for the award of UGC-BSR Faculty Fellowship.

\section{References}

[1] J. Gao, Y. He, D. Wang, Fabrication and high temperature oxidation resistance $\mathrm{ZrO}_{2} / \mathrm{Al}_{2} \mathrm{O}_{3}$ microlaminated coatings on stainless steel, Mater. Chem. Phys. 123 (2010) 731-736.

[2] G.D. Wilk, R.M. Willack, J.M. Anthony, High-k gate dielectrics, current status and materials properties consideration, J. Appl. Phys. 89(10) (2001) 5243-5275.

[3] J. Okabayashi et al., Chemical reaction and metallic cluster formation by annealing temperature control in $\mathrm{ZrO}_{2}$ gate dielectrics on Si, Appl. Phys. Lett. 85(24) (2004) 59595961.

[4] K. Sayama, H. Arakawa, Photocatalytic decomposition of water and photocatalytic reduction of carbon dioxide over $\mathrm{ZrO}_{2}$ catalyst, J. Phys. Chem. 97(3) (1993) 531-533.

[5] D.S. Lee et al., Resistance switching of the nonstoichiometric zirconium oxide for nonvolatile memory applications, IEEE Electron Dev. Lett. 26(10) (2005) 719-721.

[6] S. Venkataraj et al., Structural and optical properties of thin zirconium oxide films by reactive direct current magnetron sputtering, J. Appl. Phys. 92(7) (2002) 3599-3607.

[7] R.W. Lambert et al., Facet passivation processes for the improvement of Al-containing semiconductor laser diodes, J. Light Technol. 24(2) (2006) 956-961.

[8] K. Joy et al., Effect of sol concentration on the structural, morphological, optical and photoluminescence properties of zirconium thin films, Thin Solid Films. 520 (2012) 26832688.

[9] Y.S. Yang et al., Ferroelectricity and electric conduction characteristics of Sr-modified lead zirconium titanate thin film capacitors, J. Appl. Phys. Part I. 36(2) (1997) 749-753.

[10] L.A. Peyser et al., Photoactivated fluorescence from individual silver nanoclusters, Science. 291 (2001) 103-106.

[11] G. Slefanic, S. Music, A. Sekulic, Influence of precipitation chemistry and ball milling on the thermal behaviour of zirconium hydroxide, Thermochim. Acta. 273 (1996) 119-133.

[12] J.W. Bae et al., Preparation of $\mathrm{ZrO}_{2}$ dielectric layers by subsequent oxidation after $\mathrm{Zr}$ film deposition with negative substrate bias voltage, Metals and Materials International. 16(3) (2010) 447-452. 
[13] M.M. Larijani, E. Hasani, S. Safa, Annealing temperature effect on the optical properties of thermally oxidized nanocrystalline $\mathrm{ZrO}_{2}$ thin films grown on glass substrates, Appl. Surf. Sci. 290 (2014) 490-494.

[14] M.G. Krishna, K.N. Rao, S. Mohan, Optical and structural characterization of evaporated zirconia films, Appl. Phys. Lett. 57(6) (1990) 557-559.

[15] A. Banarji, A. Hassanpour, Modification of laser induced damage threshold of $\mathrm{ZrO}_{2}$ thin films by using time-temperature gradient annealing, Appl. Surf. Sci. 258 (2012) 2397-2403.

[16] X. Ling et al., Influence of oxygen partial pressure on the laser induced damage resistance of $\mathrm{ZrO}_{2}$ films in vacuum, Vacuum. 119 (2015) 145-150.

[17] A. Singh et al., Investigation on depth resolved composition of electron beam deposited $\mathrm{ZrO}_{2}$ thin films, Appl. Surf. Sci. 419 (2017) 337-341.

[18] W.T. Tang et al., Synthesis and characterization of $\mathrm{HfO}_{2}$ and $\mathrm{ZrO}_{2}$ thin films deposited by plasma assisted reactive pulsed laser deposition at low temperature, Thin Solid Films. 518 (2010) 5442-5446.

[19] W. Zhang et al., Infrared and Raman spectroscopic studies of optically transparent zirconia $\left(\mathrm{ZrO}_{2}\right)$ films deposited by plasma-assisted reactive pulsed laser deposition, Appl. Spectroscopy. 65(5) (2011) 522-527.

[20] S. Korkmaz et al., Thermal treatment effect on the optical properties of $\mathrm{ZrO}_{2}$ thin films deposited by thermionic vacuum arc, Vacuum. 86(12) (2012) 1930-1933.

[21] W. Li et al., Structure and properties of zirconia $\left(\mathrm{ZrO}_{2}\right)$ films fabricated by plasma-assisted cathodic arc deposition, J. Phys. D: Appl. Phys. 40(8) (2007) 2293-2299.

[22] K.P.S.S. Hembram et al., Electrical and structural properties zirconia thin films prepared by reactive magnetron sputtering, Physica B. 399 (2007) 21-26.

[23] G. Sethi et al., Influence of reactive sputterdeposition conditions on crystallization of zirconium oxide thin films, J. Vac. Sci. Technol. A. 27(3) (2009) 577-583.

[24] R. Yusoh et al., Determination of the thickness and optical constants of $\mathrm{ZrO}_{2}$ by spectroscopic ellipsometry and spectrophotometric method, Procedia Eng. 8 (2011) 223-227.

[25] S. Uthanna et al., Influence of annealing temperature on Electronic and dielectric properties of $\mathrm{ZrO}_{2}$ thin films on Si, AIP Proc. 1451 (2012)242-244.

[26] S. Zhao et al., Optical properties and structural characterization of bias sputtered $\mathrm{ZrO}_{2}$ films, J. Alloys Compd. 453 (2008) 453-457.

[27] H.H. Zhang, C.Y. Ma, Q.Y. Zhang, Scaling behaviour and structure transition of $\mathrm{ZrO}_{2}$ films deposited by RF magnetron sputtering, Vacuum. 83(11) (2009) 1311-1316.

[28] N. Li et al., Evaluation of ion conductivity of $\mathrm{ZrO}_{2}$ thin films prepared by reactive sputtering in $\mathrm{O}_{2}, \mathrm{HfO}_{2}$ and $\mathrm{H}_{2} \mathrm{O}+\mathrm{H}_{2} \mathrm{O}_{2}$ mixed gases, Thin Solid Films. 520 (2012) 5137-5140.

[29] N. Li et al., Effects of substrate temperature on the ion conductivity of hydrated $\mathrm{ZrO}_{2}$ thin films prepared by reactive sputtering in $\mathrm{H}_{2} \mathrm{O}$ atmosphere, Solar Energy Mater. Sol. Cells. 99 (2012) 160-165.

[30] U.S. Patil et al., Investigation of various properties for zirconium oxide films synthesized by sputtering, Proceedia Technol. 23 (2016) 336-343.

[31] J.H. Hong, W.J. Choi, J.M. Myoung, Properties of $\mathrm{ZrO}_{2}$ dielectric layers grown by metalorganic molecular beam epitaxy, Microelectronic Engineering. 70(1) (2003) 35-40.

[32] O. Pakma et al., Wet chemical methods for producing mixing crystalline phase $\mathrm{ZrO}_{2}$ thin film, Appl. Surf. Sci. 337 (2016) 159-166. 
[33] S. Cherneva et al., Nanoindentation investigation of mechanical properties of $\mathrm{ZrO}_{2}, \mathrm{ZrO}_{2}-$ $\mathrm{Y}_{2} \mathrm{O}_{3}, \mathrm{Al}_{2} \mathrm{O}_{3}$ and $\mathrm{TiO}_{2}$ thin films deposited on stainless steel OC 404 substrate by spray pyrolysis, Mater. Sci. Eng. B. 183 (2014) 12-16.

[34] J.J. Yu, J.Y. Zhang, I.W. Boyd, Formation of stable zirconium oxide on silicon by photoassisted sol-gel processing, Appl. Surf. Sci. 186(1) (2002) 190-194.

[35] K. Joy et al., Effects of annealing temperature on the structural and photoluminescence properties of nanocrystalline $\mathrm{ZrO}_{2}$ thin films prepared by sol gel route, J. Phys. Chem. Solids. 72 (2011) 673-677.

[36] I.J. Berlin, K. Joy, Optical enhancement of $\mathrm{Au}$ doped $\mathrm{ZrO}_{2}$ thin films by sol gel dip coating method, Physica B. 457 (2015) 182-187.

[37] J. Aarik et al., Influence of carrier gas pressure and flow rate on atomic layer deposition of $\mathrm{HfO}_{2}$ and $\mathrm{ZrO}_{2}$ thin films, Appl. Surf. Sci. 252(16) (2006) 5723-5734.

[38] B.R. Konda et al., High-k $\mathrm{ZrO}_{2}$ dielectric thin films on GaAs semiconductor with reduced regrowth of native oxides by atomic layer deposition, Chem. Phys. Lett. 583 (2013) 74-79.

[39] D.B. Cullity, Elements of X-ray diffraction, $2^{\text {nd }}$ End. Addition Wesley, 1978.

[40] G.M. Rignanese et al., First-principles investigation of high-k dielectrics, comparison between the silicates and oxides of hafnium and zirconium, Phys. Rev. B. 69(18) (2004) 184301.

[41] J. Tauc, Amorphous and liquid semiconductors, Plenum Press, New York, 1974. 